- $(\ddot{a-i j)}$

$\therefore-9$.
$\therefore 75.346$

$\equiv$

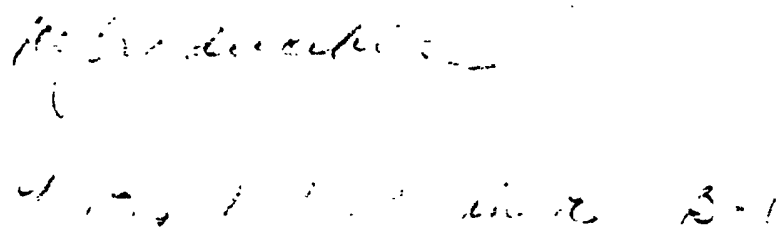

Gravity and magnetic profiles and maps,

Crump Geyser area, Oregon

By

Donald Plouff and Arthur Conradi, Jr.

U. S. Geological Survey

OPEN FILE RIFOFI $75-346$

This report is preliminary and has

pot been edited or reviewed for

conferalty with Geological Survey

standards and nomenclature.

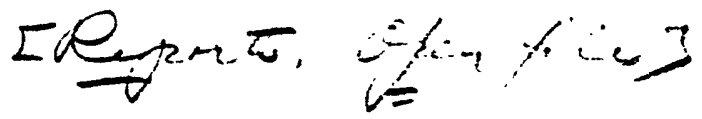

5. GEOLOGICAL SURVEY

Released: $7 / 75$

MEMO PARK

JUL ล $3 \longdiv { 9 7 5 }$

LIBRARY 


\section{MAGNETIC SURVEYS}

Truckborne magnetometer

Twelve truckborne magnetometer traverses are located near the Crump Geyser area (pl. 1). A fluxgate magnetometer, mounted about 4 metres above the ground surface, was used to continuously measure the earth's total magnetic field. The original paper chart records of the total field measurements were photographically reduced to a scale of about 1:60,000, which is nearly the same distance scale as other figures of this report $(1: 62,500)$. Circled numbers on the magnetic records (pls. 2-7) refer to location-points on the traverse map (pl. 1).

The scale on the magnetic records is 200 gammas between numbered chart lines. Datum shifts caused by rapid changes of the magnetic field offen were needed to maintain the pen position between chart lines numbered 0 to 12 . The closest four-digit push-button setting number indicated to the right of a record section is used to convert amplitudes on the chart, in terms of interpolated chart line numbers, $\underline{N}$, to values of the absolute total magnetic field, I (in gammas). The conversion formula is

$$
\mathrm{T}=48,200+200 \mathrm{~N}+2000 \mathrm{P}_{1}+400 \mathrm{P}_{3}+100 \mathrm{P}_{3}+20 \mathrm{P}_{4},
$$

where $P_{1}$ to $P_{4}$ are the respective digits in a left-to-right sequence for the push button setting.

Man-made objects such as culverts, bridges, vehicles and cattleguards produce sharp spikes on the magnetic record, which interfere with recognition of anomalies that result from geologic changes. The instrument operator has crossed out all of the anomalies that are caused by recognized man-made objects, but others may remain undetected.

The magnetic profiles (pls. 2-7) have been annotated to indicate the locations of possible faults or geologic contacts. The interpretation of these locations is based on a change in character along the magnetic record. The change in character is denoted as a local shift of magnetic level, " $L "$ ", a change of wave amplitude, "A", or a change of wavelength (average horizontal distance between magnetic peaks or troughs), "W". The letter "G" denotes a gradual change. 
A decrease of wavelength results from increasing depth of magnetic rocks beneath alluvium. Thus, a commonly-used estimate of the maximum thickness of alluvium (depth to the top of magnetic rock) can be made by measuring the horizontal extent of the steepest gradient associated with magnetic anomalies. The magnetic profiles are annotated at several places to indicate locations where maximum depths estimates might be made.

\section{Aeromagnetic survey}

An aeromagnetic survey made by the U.S. Geological Survey was flown at a nearly constant flight elevation of $2.1 \mathrm{~km}$ (7000 feet) above sea level (pl. 8). . The flight line spacing is about $1.6 \mathrm{~km}$ (one mile).

\section{GRAVITY SURVEY}

The gravity data were collected with LaCoste-Romberg Meter G17B. The values of observed gravity were tied to the datum of Behrendt and Woollard (1961). A total of 164 gravity stations provided regional control for the gravity map (pl. 9). An additional 194 gravity stations, spaced at intervals of 70 to 120 metres, were established along three traverses in the Crump Geyser area (pls. 10-12).

\section{REFERENCE}

Behrendt, J. C., and Woollard, G. P., 1961, An evaluation of the gravity control network in North America: Geophysics, v. 26, no. 1, p. 57-76. 


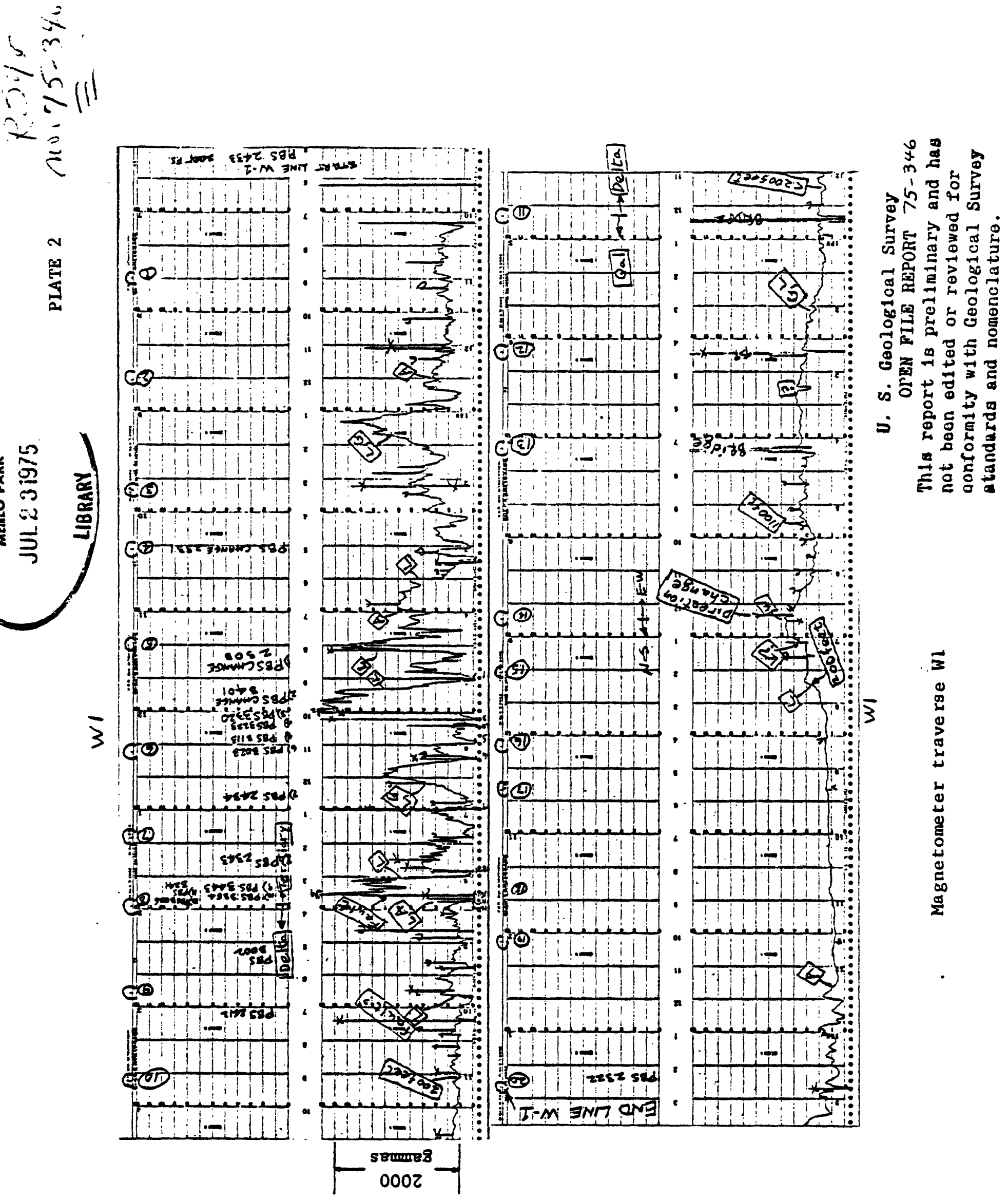


a

禹

3

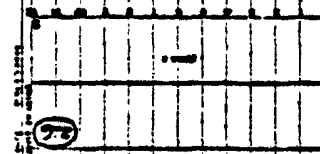

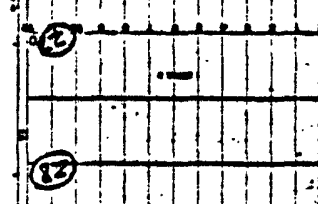

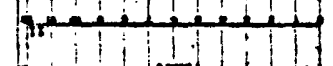

管

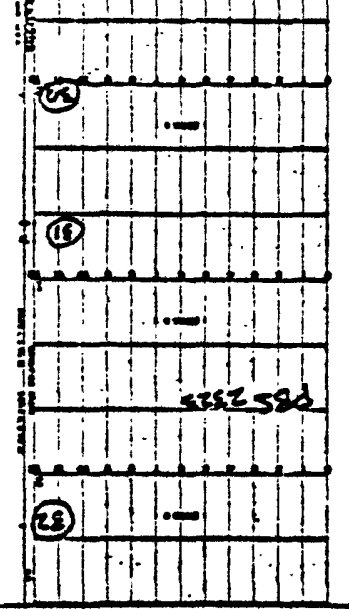

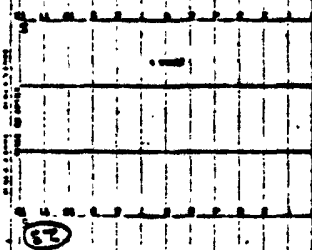

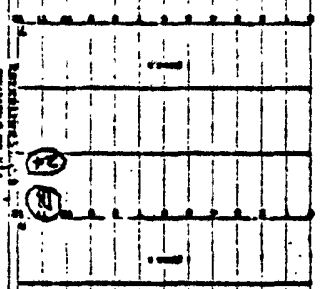

,

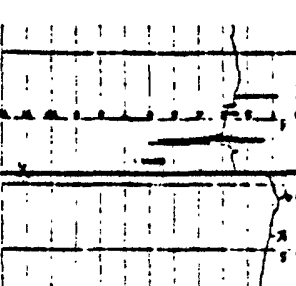

1
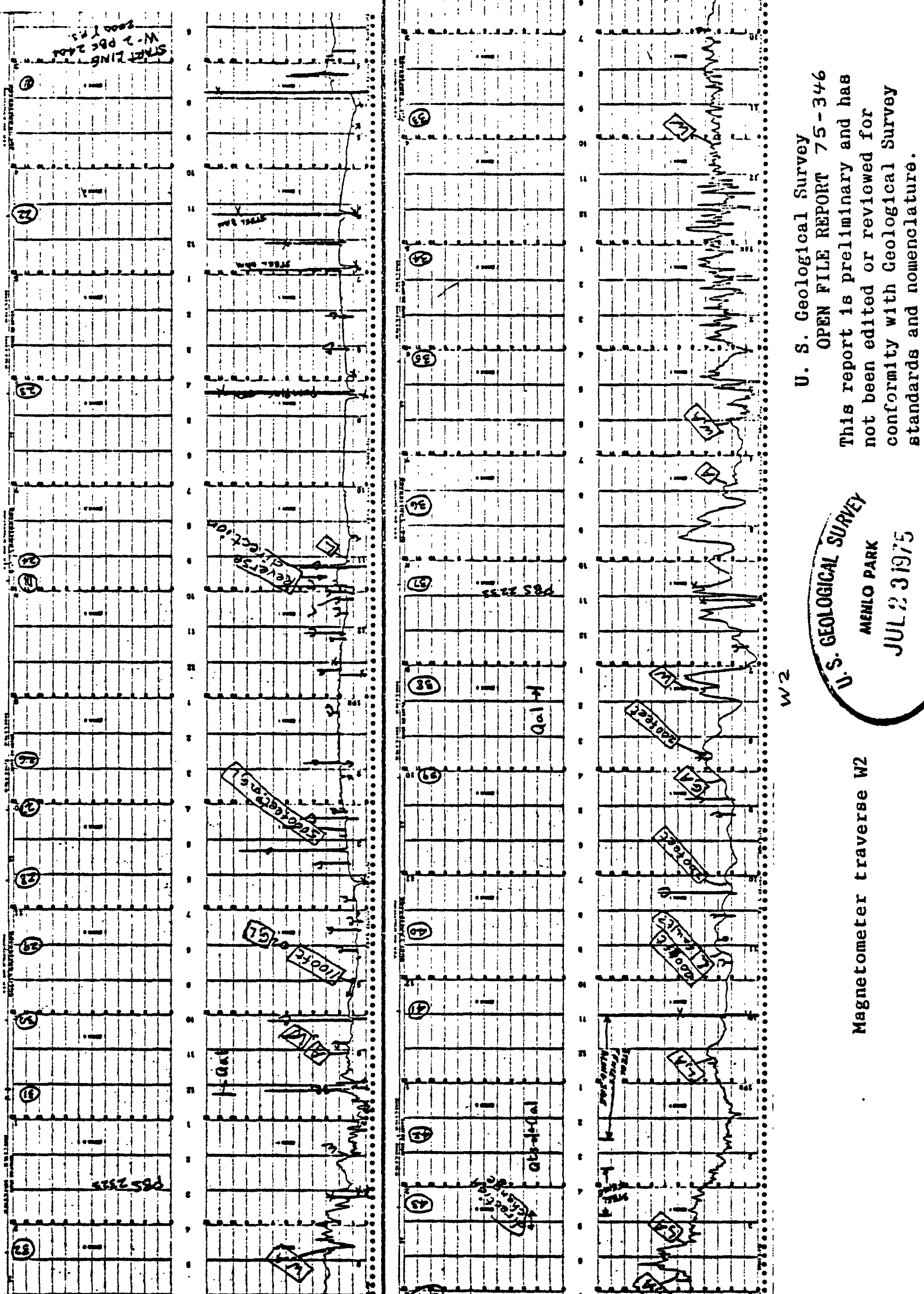

se

0002
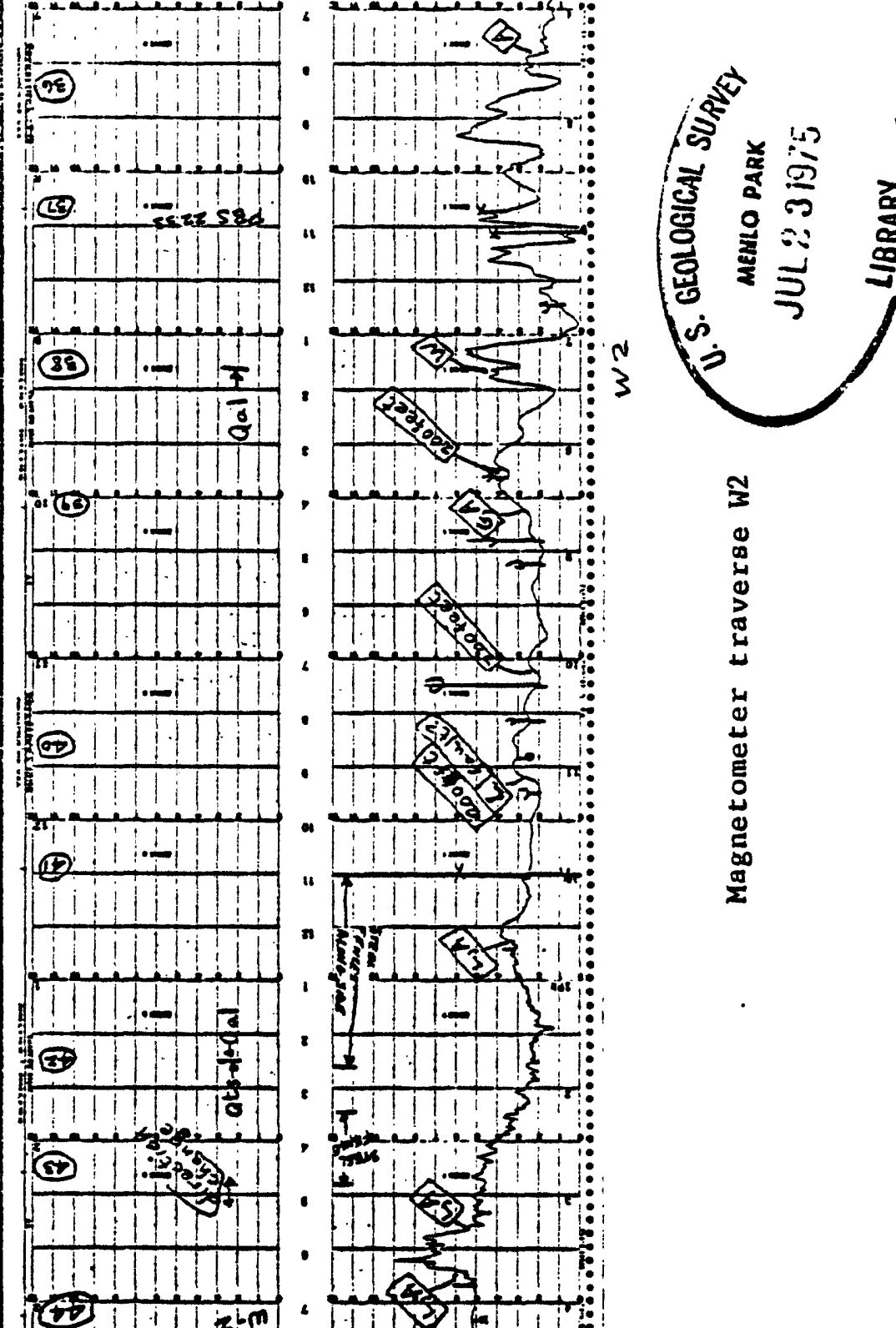

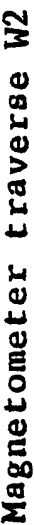



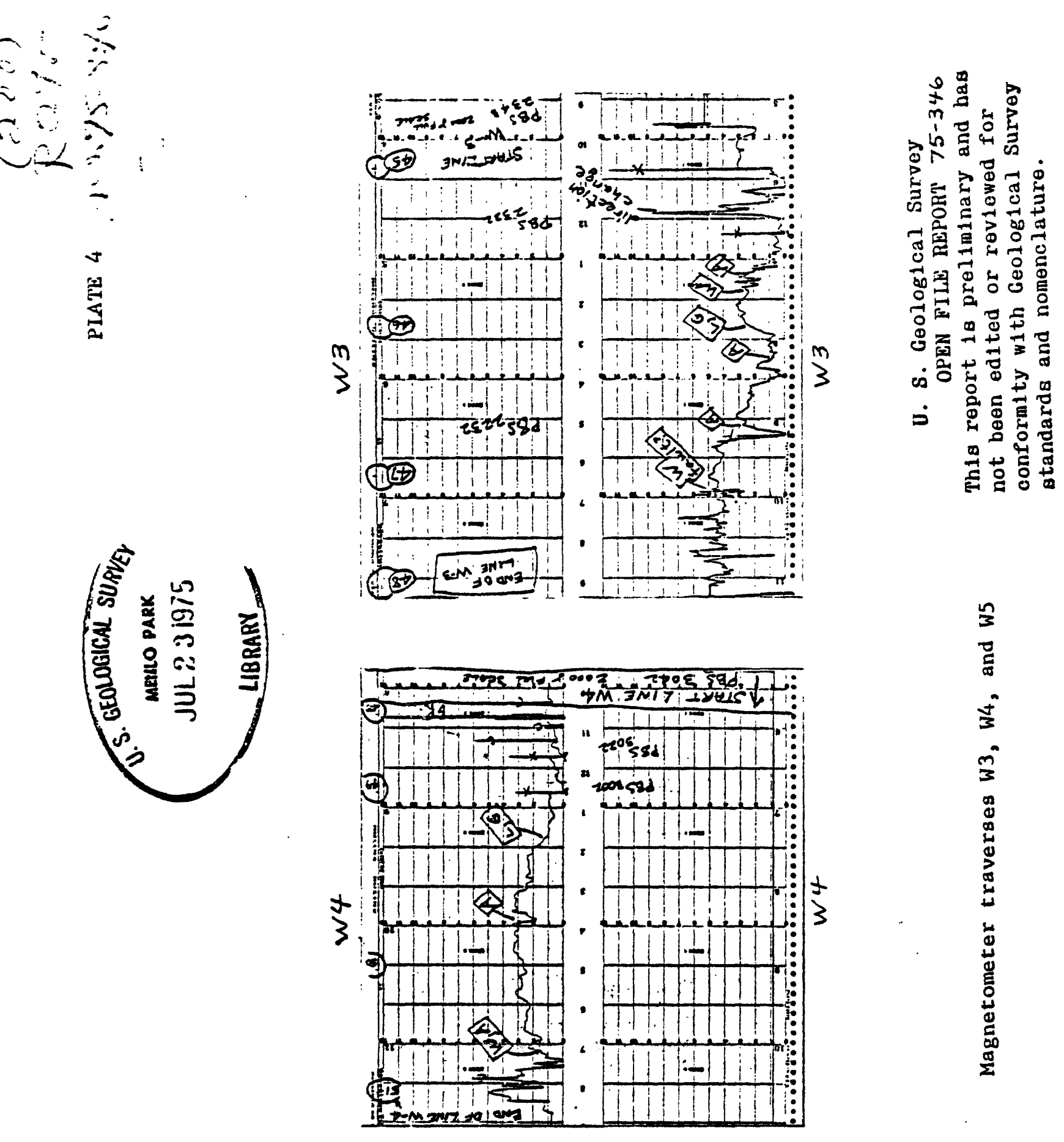

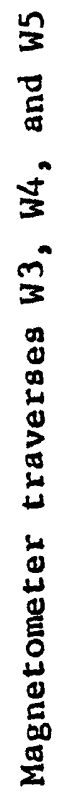

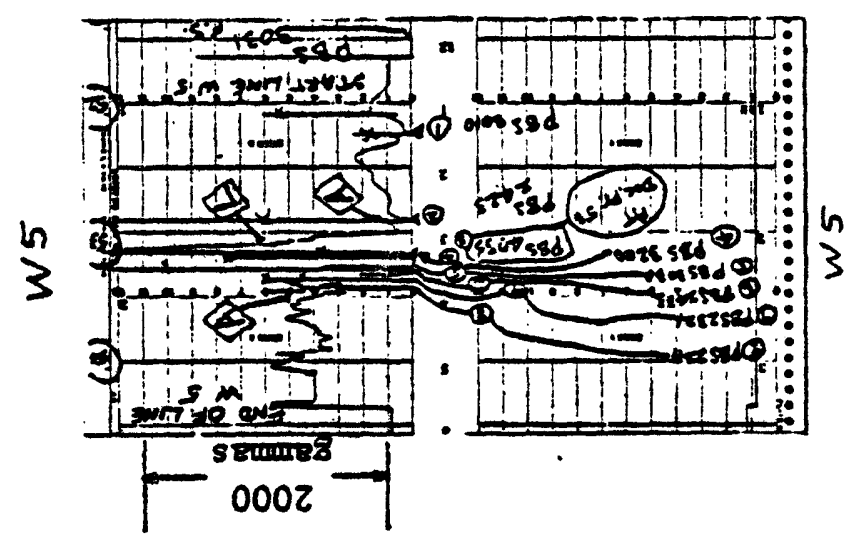



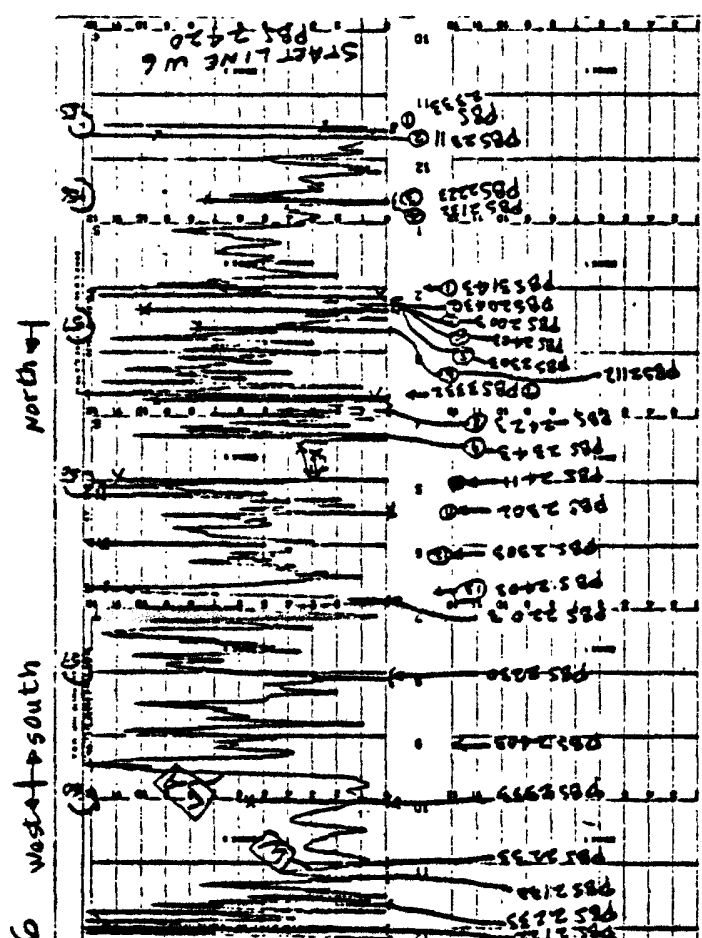

3

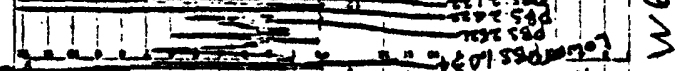

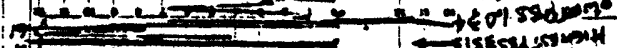

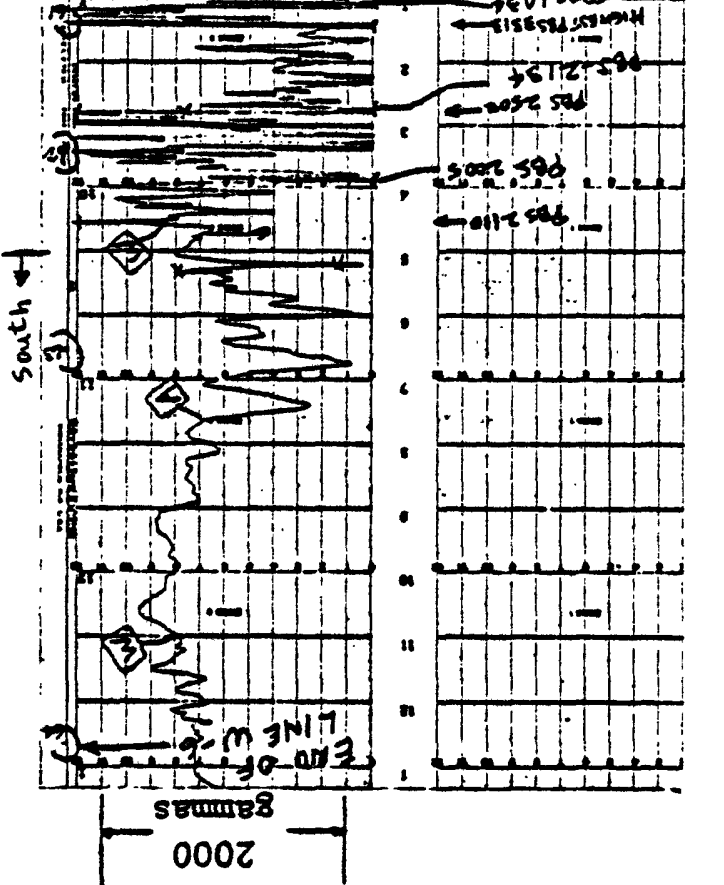

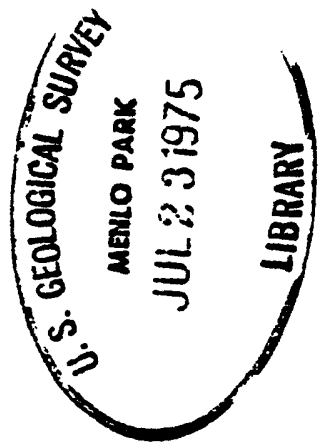

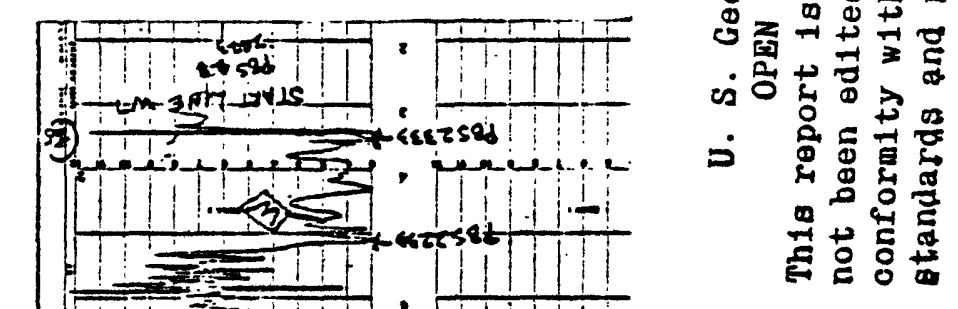

tั

$m-0$

1 व

की दूध कै

政 $\rightarrow$

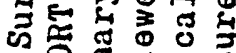

$\rightarrow \overrightarrow{\omega_{0}}$

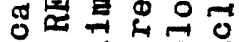

- 5 궁

열 出

牙兵 0

주욤요

영 可

- 至向

品

0 它

롱용
(20)
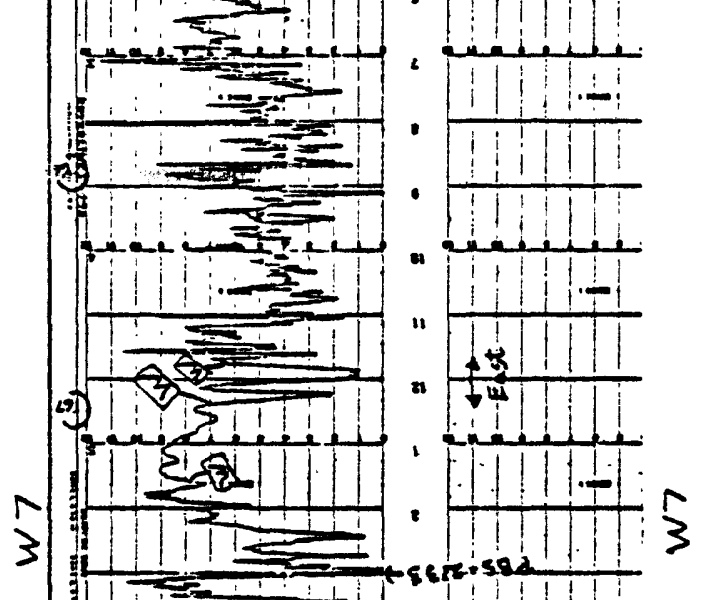

:

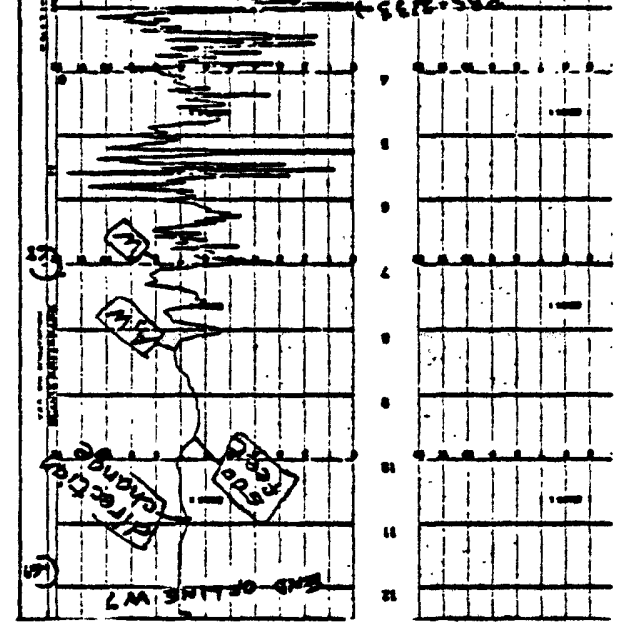




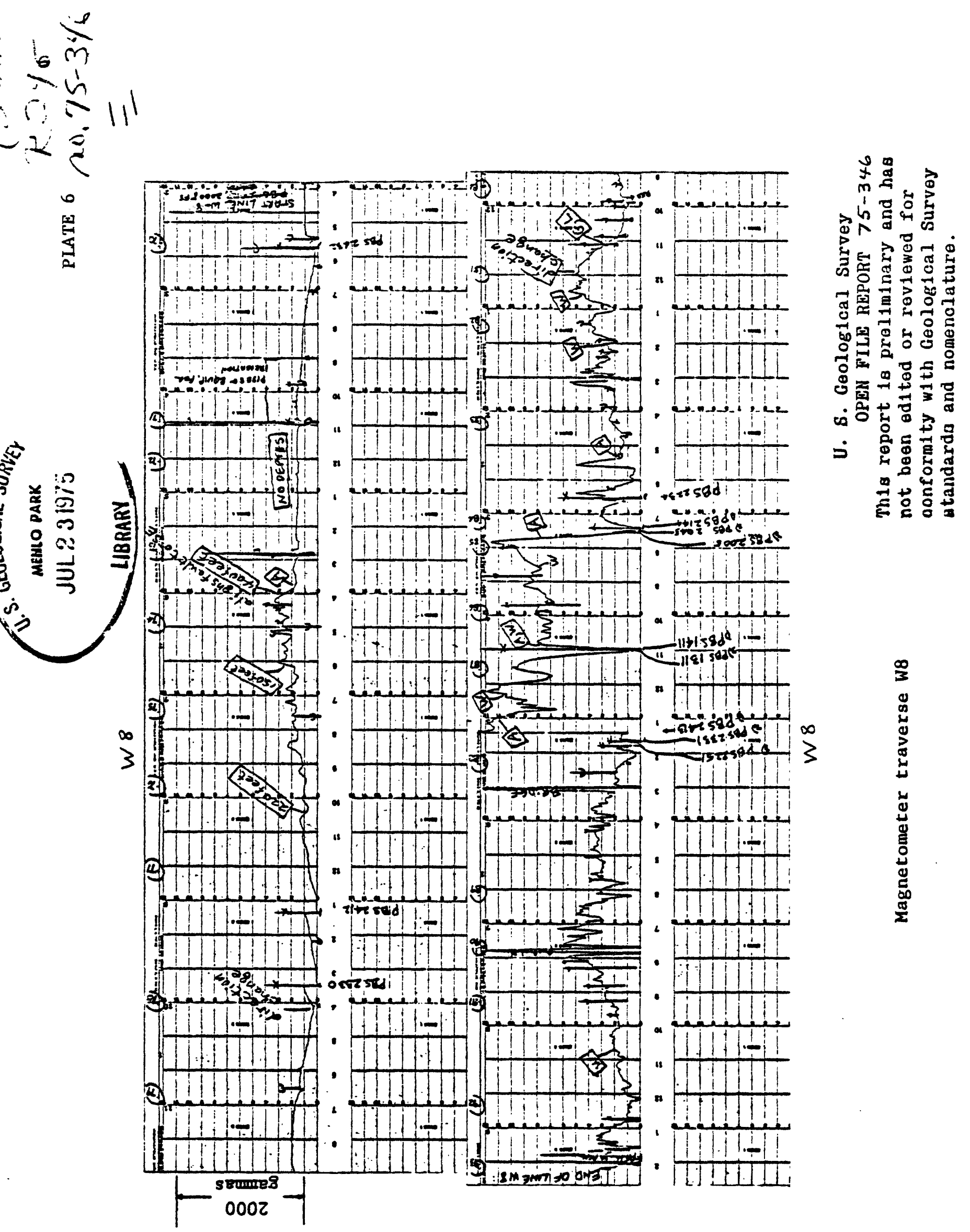




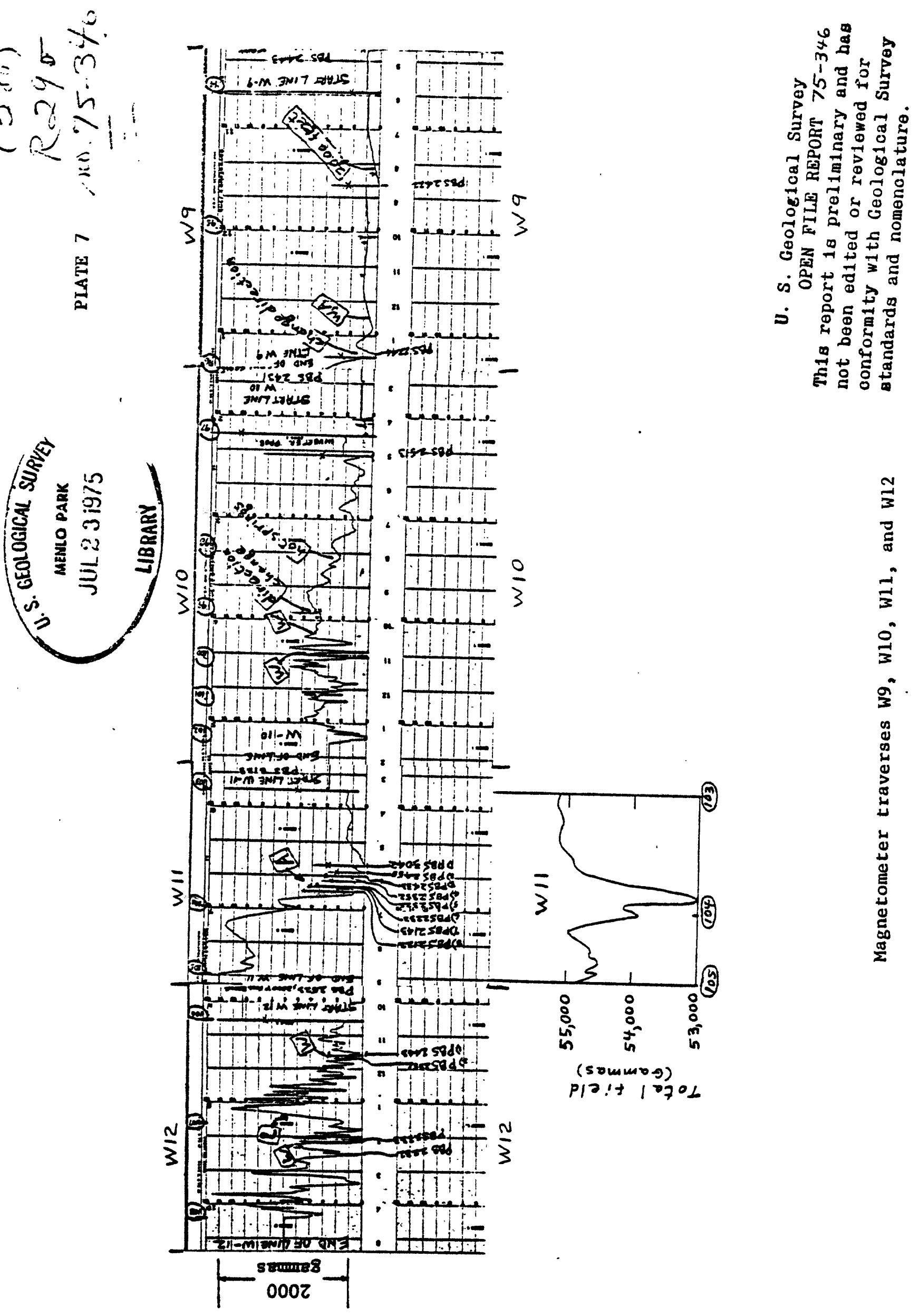




\section{$(2, \cdots)$}

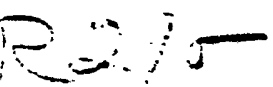

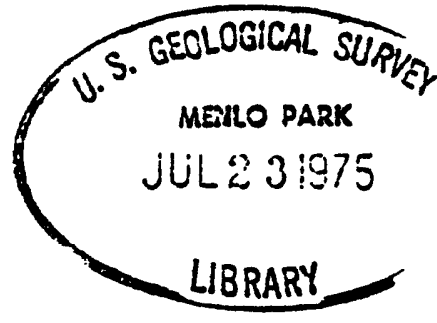

PIATE 11

$$
\therefore=75-3 \% 6
$$

B
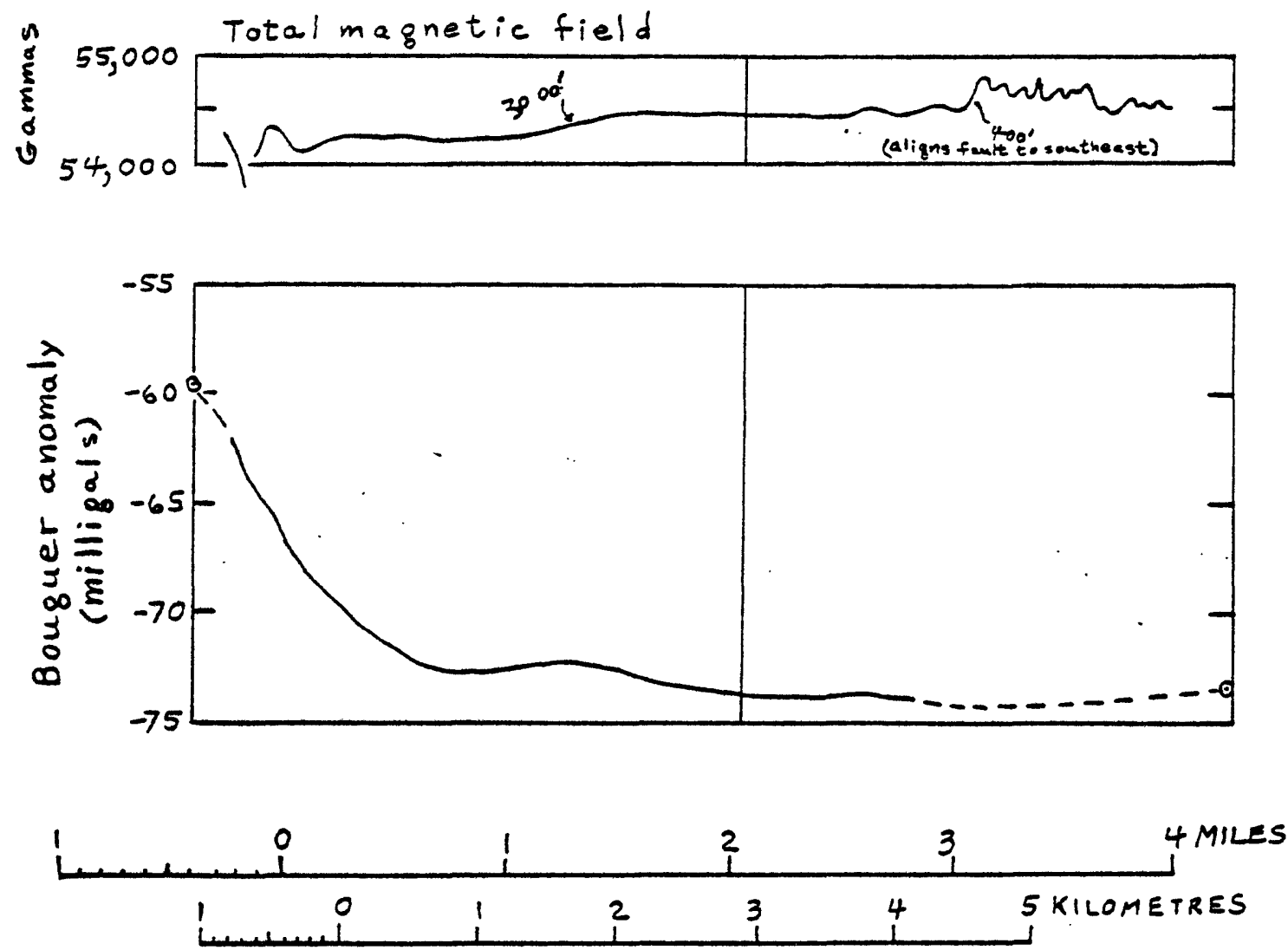

0. S. Geological Survey OPEN FIIS REPORT $75-346$

This report 18 prelininary and has

not been edited or revlewed for conformlty with Geological Survey standards and nomenclature.

Gravity and magnetic anomalies along profile $B-B^{\prime}-B^{\prime \prime}$ 

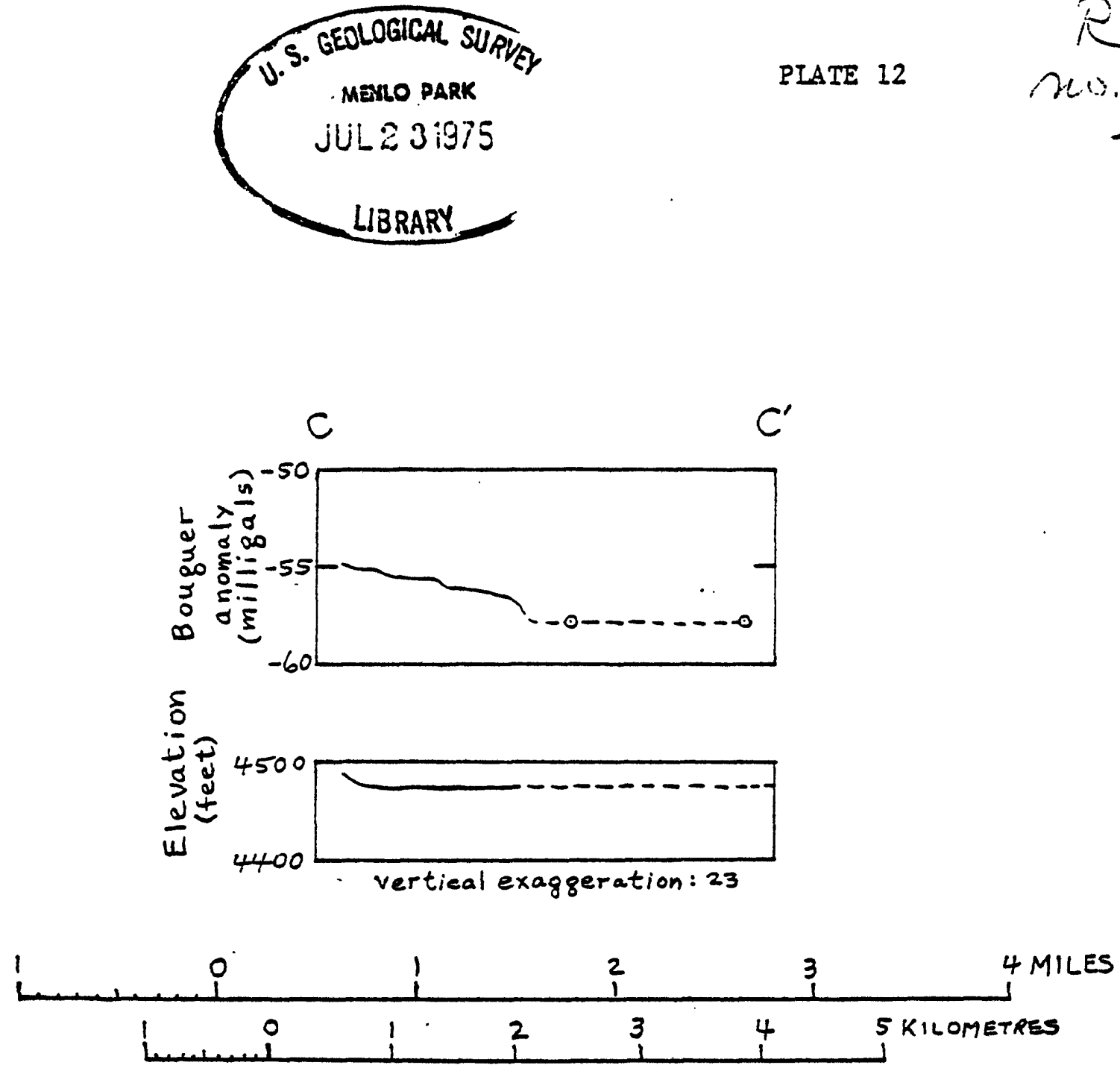

\section{U. S. Geological Surveg} OPEN FIIR REPORT 75-346 Th1s report is preliminary and bas not been edited or reviewed for conformity with Geological Survey standards and nomenclature. 